\title{
THE ROLE OF THE RADIOTHERAPIST IN THE CONTROL OF PAIN ${ }^{+}$
}

\author{
H. S. KING* M.B. Ch.B. (Witwatersrand), M.Med. (Radiotherapy) (U.C.T.)
}

It is a popular misconception that all patients with malignant disease die in great pain, in fact, few patients do have this problem. It can be dealt with by radiation - particularly for bone pain, cytotoxics, and analgesic drugs. Regular use of drugs is better than waiting for pain to become severe.

I shall be adopting a purely practical approach to this subject, as you will have heard, or be going to hear, the philosophical, psychological and spiritual approaches. I like to think that we are aware of these other aspects and are able to help the patient in these other spheres, but we are medical personnel faced with the practical management of patients with malignant disease, and terminal pain and discomfort.

Firstly, I would like to disperse the common belief that all patients with malignant disease necessarily die in great pain. In only a fairly small proportion of patients is severe pain a problem, particularly in the termingl stages. Other forms of discomfort and distress may aften be present, for we do not shuffle off this mortal coil all that easily, but even these symptoms can be dealt with if handled skilfully.

For patients who do have pain, however, we have three specific modalities - radiation, cytotoxics, and analgesic drugs.

\section{RADIATION}

This is used very often in early disease with curative intent, but in late disease it can also be a very useful modality.

\section{Bone metastases}

Breast carcinoma, bronchial carcinoma and gastrointestinal carcinomas can all metastasize to bone, and

* Radiotherapy Department, Groote Schuur Hospital and University of Cape Town.

+ Paper read at Pain Symposium, preceding 13th National Council Meeting 23-27 April 1979. these are the most common cancers in the Western world. In addition, myeloma, melanoma, thyroid tumours and a variety of other tumours may metastasize to bone, and I believe radiation to be the most effective means of dealing with this type of pain.

\section{Pressure}

For patients in whom pressure on nerves or other organs may cause pain, radiation may be a rapid means of alleviating the latter. The nerves involved may be the brachial plexus, sciatic nerve, or those in the retroperitoneal region. These, being local problems, are best treated with a local form of therapy, even in late disease.

\section{Enlarged organs}

Gross enlargement or distension of organs due to tumour may cause severe pain. This may be relieved by irradiation by reducing the bulk.

\section{CYTOTOXICS}

- Cytotoxics can be used in combination with irradiation in all these instances, but they are seldom effective on their own except in very sensitive tumours or where irradiation has already been used. However, even sensitive tumours such as lymphomas and seminimas, may need to be treated with irradiation if they have metastasised to bone.

\section{ANALGESIC DRUGS}

Patients who present a problem with pain may have developed a problem because their doctors are fearful of addiction. I do not believe that this is a factor in patients with severe pain due to malignant disease. 


\section{Mild pain}

We usually start by drugs that are not habit forming; these can be very effective and often all that a patient may need, even in the terminal stages of their illness. Aspirin with or without codeine, and paracetamol with or without codeine, may be particularly useful in old patients in whom the effect of aspirin on the stomach needs to be avoided; dextropropoxyphene, either alone or with aspirin may also be used.

\section{Moderate pain}

Tilidine hydrochloride (Valoron) is useful as an added drug at night or alternating with the abovementioned during the day if the pain is moderately severe. It is also available in drops. Dipanone hydrochloride (Wellconal) is a useful oral preparation in the same context, but can occasionally make patients confused.

\section{Severe pain}

The opiates may be given by mouth, e.g. oral Omnopon tablets or morphine in chloroform exlixir. In the terminal phase of an illness, these are more effective when combined with the phenothiazines, which also prevent vomiting and act as tranquillizers.
Many of you will recently have heard Dr. Cicely Saunders of St. Christopher's Hospice in London. At the Hospice they have found that morphine is the most useful drug and give it in a dose range of $5 \mathrm{mg}$ (for terminal sedation only) to $60 \mathrm{mg}$ for severe pain, and even up to $120 \mathrm{mg}$. I have used oral Omnopon in doses up to $60 \mathrm{mg}$ in patients being nursed at home, with good control of pain.

The regular use of analgesics is most important. Drugs should never be prescribed p.r.n. especially for severe pain, but should be given regularly when the patient experiences minimal pain. If one waits till the pain is more severe, muscle spasm and tension have added to the problem and the patient requires larger doses to eliminate the pain.

I have not gone into the details of the management of the other distressing symptoms in terminal illness, since this was not required of me, but obviously the skilful management of these symptoms is most important. I have also not discussed how, in some circumstances, we seek the assistance of the Pain Clinic, staffed by an anaesthetist and a neurosurgeon, to help us cope with some forms of intractable pain in whom nerve blocks may be useful. I hope, however, that I have given you some practical ideas on how we, as radiotherapists/oncologists, are required to approach the problem of pain associated with malignant disease. 